Istanbul Finance Congress, November 1-2, 2018, Istanbul, Turkey.

\title{
CAPITAL FLOWS AND CONTROL MECHANISMS
}

\section{DOI: 10.17261/Pressacademia.2018.979 \\ PAP-IFC- V.8-2018(11)-p.46-50}

\section{Meliha Burcu Kines}

Okan University, School of Business and Management Sciences, Tuzla Campus, Istanbul, Turkey. burcu.kines@okan.edu.tr ORCID: 0000-0002-2840-4379

\section{To cite this document}

Kines, M. B. (2018). Capital flows and control mechanisms. PressAcademia Procedia (PAP), V.8, p.46-50.

Permemant link to this document: http://doi.org/10.17261/Pressacademia.2018.979

Copyright: Published by PressAcademia and limited licenced re-use rights only.

\section{ABSTRACT}

Purpose - In our days, the acceleration of capital flows between countries causes debates on current economics theories and policies. Capital flows between countries mainly specified as "hot money" may create severe problems for home countries since they may outflow suddenly for varied reasons. The purpose of this study is to investigate the reasons for sudden stop of capital flows in developing and underdeveloped countries and the efficiency of some control mechanisms.

Methodology - In this study, the fundemental changes of foreign capital flows in home countries, the main reasons causing outflow and the efficiency of basic control mechanisms are investigated theoritically based on the literature review.

Contribution- It is observed that at the beginning stage there is a need of control mechanisms for short term capital flows in order to eliminate their negative effects.

Conclusion- In conclusion, it can be said that in the case of adopting an economic development and growth model financed by foreign direct investment and internal resources, Turkey, like South Corea, will acquire the potential of being between the biggest economies around the World.

Keywords: Capital flows, control mechanisms, hot money, foreign direct investment, sudden stop.

JEL Codes: O10, 020, 030

\section{SERMAYE HAREKETLERI VE KONTROL MEKANIZMALARI}

\section{ÖZET}

Amaç- Özellikle son yıllarda ülkeler arasında artan yoğun sermaye hareketleri, mevcut ekonomi teori ve politikalarının da tartışılmasına sebep olmuştur. Başta "sıcak para" olarak adlandırılan kısa vadeli sermaye akımlarının ülkelere yatırım yapıp, koşullar değişince ani bir şekilde kaçması birçok problemin doğmasına yol açmıştır. Bu çalışmanın amacı, özellikle az gelişmiş ya da ülkemizin de dahil olduğu gelişmekte olan ülkelere yatırım yapan sermaye akımlarının kesintiye uğramasının nedenlerini sorgulamak ve aynı zamanda sermaye kontrollerinin etkili olup olmadığı konusunu irdelemektir.

Metodoloji- Bu çalışmada, teorik olarak yabancı sermaye akımlarının girdiği ülkelerde yol açtığı temel değişiklikler, kaçmasına sebep olan başlıca unsurlar ve sermaye kontrol mekanizmalarının etkinliği literatür taraması temel alınarak irdelenmektedir.

Katkı- Kısa vadeli sermayenin olası olumsuz etkilerini bertaraf etmek için başlangıç noktasında sermaye kontrol mekanizmalarına ihtiyaç olduğu gözlenmektedir.

Sonuç ve Öneriler- Sonuç olarak; doğrudan yabancı sermaye ve/veya iç kaynaklarla finanse edilen bir ekonomik kalkınma ve büyüme modelinin benimsenmesi halinde Türkiye, Güney Kore örneğinde olduğu gibi dünyanın büyük ekonomileri arasında yer edinme potansiyeline sahip olacak bir ülkedir.

Anahtar Kelimeler : Sermaye hareketleri, kontrol mekanizmaları, sıcak para, doğrudan yabancı sermaye, ani duruş JEL Kodları: O10, O20, O30 


\section{GiRiş}

Özellikle son yıllarda ülkeler arasında artan yoğun sermaye hareketleri, mevcut ekonomi teori ve politikalarının da tartışılmasına sebep olmuştur. Başta "sıcak para" olarak adlandıılan kısa vadeli sermaye akımlarının ülkelere yatırım yapıp, koşullar değişince ani bir şekilde kaçması birçok problemin doğmasına yol açmışır. Ekonomik büyüme ve kalkınma için sermayeye ihtiyaç duyan az gelişmiş ya da gelişmekte olan ülkeler, sermaye akımlarını teşvik edici ekonomi politikalarını benimsemişlerdir. Her ne kadar sermaye girişi ülkeler açısından olumlu bir unsur olarak kabul edilse bile; doğrudan yatııım şeklinde olmayan sermaye akımlarının temel güdüsü kısa sürede kar elde ederek başka ülkelerdeki yatırım alanlarına yönelmektir.

Süresi ne olursa olsun; yabancı sermayenin geldiği ülkede yarattığı başlıca etki, refah seviyesini artırmak yönündedir. Söz konusu olumlu etkinin temel sebepleri; döviz kurunun düşmesi ve dolayısıyla ithalatın artarak ülkeye ucuz malların gelmesi, buna bağlı olarak ülke içindeki enflasyonun aşağıya çekilebilmesi ve yerli para bazında belirlenen milli gelir, kişi başına düşen gelir, dı̧̧ borç vb. temel makroekonomik göstergelerin iyileşme göstermesidir. Ülke yönetiminde söz sahibi olanlar açııından bakıldığında; bu olumlu tablonun sürdürülebilmesi gayreti içinde oldukları gözlenmektedir. Yanıtlanması gereken soru ise bu işleyişin ne kadar sürdürülebilir olduğunu göz önüne alarak bazı mekanizmalar geliştirmek suretiyle sermaye akımlarını lehte bir duruma çevirmenin mümkün olup olmadığıdır?

Az gelişmiş ve/veya gelişmekte olan ülkeler için kalkınma stratejisi, yerli paranın değerinin düşük tutulması ve ihracatın teşvik edilerek ithalatın kontrol altına alınması olmalıdır. Bununla birlikte; günümüzde birçok az gelişmiş veya gelişmekte olan ülkenin bu stratejiye bağıı kalmayıp tam ters yönde bir politika izlediği görülmektedir. Dışarıdan kaynak girişini sağlamak için, ülke içindeki faizlerin yükselmesini teşvik etmekte ve faiz artışları ülke içinde temel makroekonomik sorunlar da yaratmaktadır. Son 3-4 ay hariç olmak üzere, uzun süredir güçü seyreden Türk lirası sonucu, sanayimizin rekabet gücünün zayıfladığı ve aynı zamanda üretimimizin de önemli ölçüde ithalata bağımlı hale geldiği gözlenmektedir. Son yıllarda, Türkiye'de büyümenin sıcak paraya endeksli olduğu, dışarıdan kaynak girişi durursa büyümenin sekteye uğrayacağı görülmektedir. İzlenen ekonomi politikalarına bağlı olarak; yurt içindeki tasarruf oranı \%14 seviyesine gerilemiş ve cari açık ise GSYiH'nın \%6 seviyelerine ulaşmıştır. Son dönemde ise; ekonomik faaliyetlerdeki daralma neticesinde cari fazla verilmeye başlanmışırı. Söz konusu veriler bize; Türkiye'nin mevcut ekonomi ve sanayi yapısıyla hedeflenen büyümenin yakalamasının bedelinin yüksek ve sürdürülemez olduğu yönündedir.

Bu çalışmanın amacı, özellikle az gelişmiş ya da ülkemizin de dahil olduğu gelişmekte olan ülkelere yatırım yapan sermaye akımlarının kesintiye uğramasının nedenlerini sorgulamak ve aynı zamanda sermaye kontrollerinin etkili olup olmadığı konusunu irdelemektir. Sermaye açı̆̆ı ile karşı karşıya kalan ülkelerin, düşük büyüme ve gelir yaratma unsurlarına bağlı olarak dış finansmana gereksinme duymaları kaçınılmaz bir olgudur. Öte yandan, sermayenin temel motivasyonu giriş yaptığı ülkeleri kalkındırmaktan ziyade, kısa sürede yüksek kar etmek ve yeni yatııım alanlarına yönelmektir. Az gelişmiş ve/veya gelişmekte olan ülkeler açııından sağlıkı ve sürdürülebilir bir ekonomik kalkınma için gerekli olan dış finansmana yönelik kimi tedbir ve kontrol mekanizmalarının işlevselliği araştıııımalıdır. Bu çalışmada, teorik olarak yabancı sermave akımlarının girdiği ülkelerde yol açtığı temel değiş̧iklikler, kaçmasına sebep olan başlıca unsurlar ve sermaye kontrol mekanizmalarının etkinliği irdelenmektedir.

\section{LITERATÜR TARAMASI}

Ülkeler arasında yoğun olarak görülen sermaye hareketlerinin makroekonomik göstergeler üzerindeki etkisi ve sermaye kontrol mekanizmaları ile ilgili olarak günümüzde akademik çalışmalar yoğunluk kazanmıştır. Serbestçe dolaşan ve ani çıkış yaptı̆̆ı zaman ülkelerde tahribat yaratan sermayeye yönelik kontrol mekanizmaları ve araçları sorgulanmaya başlanmışıı. Söz gelimi Çin, dışarıdan yüksek tutarda sermaye çeken bir ülke olarak uzun yıllar boyunca parasını dolara karşı düşük tutmuş ve özellikle doğrudan yabancı sermayeyi teşvik edici politikaları uygulamıştır.1

Minsky (1993), finansal istikrarsızlık hipotezinde kapitalist bir ekonomik sistemde, reel sektör ile finans sektörü arasında güçlü bir bağ olduğunu vurgulamıştır.2 Kapitalist bir ekonomik düzenin sağlıklı işleyişinin sürdürülmesi için gerekli olan unsurun ise, gelecek dönemlere yönelik kar beklentilerinin olduğuna işaret etmiştir.

Yabancı kaynak girişinin sağladığı kısa süreli olumlu faktörlerin etkisi uzun hatta orta vadede ortadan kalkmakta, bunun yanı sıra bu süreçte yerli sanayinin rekabet gücü zayıflamakta ve ihracat da ithalata bağımlı bir hale gelmektedir. Sağlıklı bir iktisat politikası öncelikli olarak; arz yönünü, üretkenlik ve girişimciliği, rekabetçi ve düzgün işleyen bir piyasa ortamında teşvik edici yönde olmalıdır.3

Sermaye hareketlerini inceleyen akademik çalışmalar, 1994 yılında gerçekleşen Meksika Tekila Krizi'nden sonra artış göstermiştir. Söz konusu çalışmalarda elde edilen ortak bulgu ise cari işlemler açığının milli gelire oranının \%9-10 seviyesine yükselmesinin krizin bir öncü göstergesi niteliği taşıdığıdır. Bunun yanı sıra; o dönemde Meksika'da olduğu gibi ülke düşük tasarruf oranlarına sahipse; krizlere karşı kırılganlığının daha yüksek olduğu da vurgulanmıştır. Öte yandan, yüksek iç tasarruf oranlarına ve cari açık fazlasına sahip Asya ülkelerinin de 1997-1998 yıllarında krize girmesi, akademik çalışmalarda elde edilen bulguların yeniden ele alınmasına ve irdelenmesine sebep olmuştur.4 Akademik çevrelerde 1997-1998 yıllarında Asya ülkelerinde yaşanan krizin oluşmasında, yüksek tutardaki kısa vadeli dış borçlanmanın da büyük bir etkisinin olduğu hususu genel kabul görmüştür. Sermaye çııışının hızlandıran etkenler arasında, cari açı̆̆ın yüksekliğinin yanı sıra ülkedeki dolara bağı borçlanma artışııın olduğu yapılan çalışmalarda belirtilmiştir.5

${ }^{1}$ Brookings Institute, Rethinking Central Banking, Committee on International Economic Policy, September 2011, p.16.

2 Hyman P. Minsky, "The Financial Instability Hypothesis", Radical Political Economy, Ed. by Philip Arestis, Malcom Sawyer, Edward Elgar : Aldershot, New York, 1993.

3 M. Merih Paya, Küresel Ortamda İktisat Politikaları, Türkmen Kitabevi, 2013, s.306.

4 Guillermo A. Calvo, "Capital Flows and Capital Market Crisis: The Simple Economics of Sudden Stops", Journal of Applied Economics, 1(1), 1998, p. 36

5 Guillermo A. Calvo, Alejandro Izquierdo, Luis Fernando Mejia, "On the Empirics of Sudden Stops: The Relevance of Balance Sheets Effects", NBER Working Paper, No 10520, 2004, p.22. 
Sermaye hareketleri kapsamında hazırlanan akademik çalışmalarda, özellikle sermayenin kısa vadeli olmasının, ülkeleri krizlere karşı daha kırılgan bir niteliğe büründürdüğüne işaret edilmiştir. Bu noktada sorulması gereken başlıca soru ise sermaye kaçışının neden ülkede istikrarsızlığa yol açtığıdır. Sonuçta, sermaye kaçışı sonucu ekonomide yeni dengeler şekillenecek, yerel paranın değer kaybetmesi neticesinde de ithalat azalırken ülkenin ihracat potansiyeli artacaktır. Söz konusu soruya cevap, ani sermaye çıkışının mali sektörü çok hızlı ve olumsuz olarak etkilemesinde aranmalıdır. Özellikle mevduat sahiplerinin durumdan tedirgin olarak bankalardan para çekmesi ve bu durumu takiben reel sektöre kredi kanallarının kapanması üretim sürecini sekteye uğratmaktadır. Bunun yanı sıra, ülke sanayisinin hammadde ve ara mamul bazında yoğun ithal girdi kullanması yaşanan devalüasyon sonucu üretim maliyetlerinin yüksek oranda artmasına sebep olmaktadır. Bu kapsamda, Güney Kore'nin sanayisini negatif dış faktörlere karşı koruyan politikaları uygulaması, ekonomik büyüme modelinin performansında ana unsur olarak kabul edilmektedir.6 Amerika Birleşik Devletleri’nde 1929 yılında yaşanan Büyük Buhran krizi sürecince çöken iç talep; Keynesyen önlemler ve maliye politikalarının uygulanması sonucu uzun zaman sonra telafi edilebilmiştir. Her ne kadar Büyük Buhran'ın olumsuz etkileri yıllar boyunca sürmüş olsa da; şu an karşılaşılan finansal krizlerin yarattığı tahribat daha fazla ve düzelme süreci daha uzun sürelidir. Bu durumun ana sebebi; günümüzde sermaye akımların çok yoğun olarak ülkeler arasında dolaşması ve buna bağlı olarak para ve maliye politikalarının etkinliğinin azalmasıdır. Sermaye çıkışı sonucu kriz ile karşı karşıya kalan ülkeler de, çıkış yolu olarak Uluslararası Para Fonu'na (IMF) başvurmakta fakat ne yazık ki kemer sıkıcı IMF programları da ekonominin düzelmesi hususunda etkin olamamaktadır. Yürütülen akademik çalışmalarda, cari açık fazlalığının yüksek olmasına ek olarak ülkedeki yabancı para bazlı borçlanmanın artmasının da sermayeyi ürküten ve dışarıya kaçmasına sebep olan bir etken olduğu vurgulanmıştır.7

Sermaye hareketleri kapsamında bir ülkenin doğrudan yabancı sermayeyi teşvik edici politikalar izlemesi ve bu yolu finansman açı̆̆ını gidermeye yönelik bir araç olarak görmesi mümkündür. Ancak kimi zaman doğrudan yabancı yatırımların da yurtdışına kar transfer ederek ödemeler dengesi nezdinde sıkıntı yaratabileceği hususu göz ardı edilmemelidir.

Sonuçta; günümüzde sermaye hareketleri ve kontrol mekanizmaları üzerine hazırlanan akademik çalışmaların yoğunlaştığı görülmektedir. Bu noktada; sermaye kontrollerinin ise ne zaman, bir başka deyişle fonların ülke girişinde mi yoksa çıkışında mı uygulanacağı konusu da önem arz etmektedir. Öte yandan; yapılan çalışmalar, sermaye kontrollerinin etkin olma durumunun zamanlamadan ziyade, giriş yaptığı ülkedeki ekonomi politikalara göre şekillendiğini belirtmektedir. Bu konuda Brezilya, karşımıza önemli bir örnek olarak çıkmaktadır. 1990’ı yıllarda fon akımlarının kontrolü için Tobin vergisini yürürlüğe sokan Brezilya başarısızlığa uğramıştır. Söz konusu başarısızlığın temel nedeni; Brezilya Merkez Bankası'nın o sırada uyguladığı sterilizasyon programıdır. Sermayenin ani kaçışını durdurmak için bir araç olarak belirlenen verginin etkinliği, sterilizasyon programı sonucu faizlerin yükselmesiyle azalmış ve vergi uygulanmasına karşın ülkeye fon girişi devam etmiştir.8 Akademik çevrelerde; piyasa işleyişi ile uyumlu olsa bile, sermaye kontrollerinin kısmen kısa vadede etkin olabileceği, uzun vadede ise sermaye kontrolleri uygulamasının başarılı olamayacağı anlayışı geçerliliğini korumaktadır.

\section{KATKI}

1990’lı yıllarda uygulamaya başlanan liberal ekonomi politikalarının, istikrar sağlaması hedeflenirken tam tersine özellikle az gelişmiş ve gelişmekte olan ülkelerde belirsizlikleri ve dalgalanmaları arttırdığı gözlenmektedir.9 İzlenen liberal iktisat politikaları çerçevesinde denetim ve kontrol mekanizmaları gevşetilmiş; sermayenin ülkeler arasında serbestçe dolaşmasına imkan tanınmıştır.

Bir ülkeye gelen sermayenin kısa vadeli olmasının ve doğrudan yatırıma yönelmemesinin en büyük sebebi, ülkelerin makroekonomik dengelerine ve aynı zamanda yürürlükte olan ekonomi politikalarına duyulan inanç ve güvendir. Uygulanan iktisat politikalarının geçici, günü kurtarmaya yönelik önlemler kapsamında değerlendiren fon sahipleri; ülkelere çoğunlukla kısa vadeli olarak giriş yapmakta ve yeterli düzeyde kar elde edince de ülkeyi terk etmektedirler.

Söz konusu ülkelere gelen sermaye daha çok likiditesi yüksek finansal araçlara yatırım yapmakta ve özellikle gelişmiş ülkelere oranla yüksek seyreden faiz avantajından faydalanmayı hedeflemektedir. Bu durum, esasında az gelişmiş ve/veya gelişmekte olan ülkelerin açısından kısa vadeli bir finansman kaynağını temin edebilmek için ağır bedeller ödenmesi gerektiğine işaret etmektedir. Bu olgunun bilincinde olarak; kalkınma ve büyüme için dış kaynağa gereksinim duyan ülkelerin öncelikli olarak kısa vadeli, geçici sermayeye karşı bazı kontrol mekanizmaları ve vergi uygulamaları geliştirebilmeleri gerekmektedir.

Olası sermaye kontrollerinin başlıca iki önemli niteliği göze çarpmaktadır: 1) Asimetrik yapıları ve 2) Geçici olmaları10. Sermaye kontrollerinin asimetrisi, uygulamanın çoğunlukla girişlerde yapılırken, çıkışlarda uygulanmaması hususundan oluşmaktadır. 1990’lı yıllardan itibaren ülkelerin sermaye kontrolleri için değişik araçlar kullandığı gözlenmektedir. Söz gelimi; 1995 yılında Çek Cumhuriyeti kısa vadeli sermayeye yönelik olarak miktar kısıtlamasında bulunmuş, Brezilya ise 1993-1997 yılları arasında yabancı sermaye üzerine vergi koymuştur. 1995-1997 yılları arasında Tayland, ulusal bankaların off-shore borçlanmalarını sınırlama yoluna gitmiş, Şili ve Kolombiya da sermayeyi vergilendirmiştir. Sermaye kontrol araçlarının geçici olması ise, sermaye girişlerinin yavaşlaması ve/veya azalması sonucu, uygulamanın da azaltılması ya da tamamen ortadan kaldırılması durumunu tanımlamaktadır.

Uygulanan sermaye kontrollerinin sermaye üzerindeki etkisi incelendiğinde; özellikle gelen fonların yapısını ve aynı zamanda miktarını değiştirdiği görülmektedir. Bu bağlamda, neden sermaye girişlerine yönelik bir kısıtlamaya ihtiyaç duyulduğu sorusunu vurgulamak gerekmektedir. Sonuçta; kısa ya da uzun olsa da sermaye girişinin iç talebi de artırarak ekonomik canlanma sağladığı görüşü gündeme gelebilir. Sorunun yanıtı ise, gelen sermayenin çoğunlukla tüketim harcamalarını artırması durumunun da sürdürülemez olduğu ve uzun

6 H. J. Chang, The Political Economy of Industrial Policy, St. Martin's Press, New York, 1994, pp. 91-136.

7 Guillermo A. Calvo, Alejandro Izquierdo, Luis Fernando Mejia, "On the Empirics of Sudden Stops: The Relevance of Balance She ets Effects", NBER Working Paper, No 10520, 2004, p.22.

8 Nicolas E. Magud, Carmen M. Reinhart, Esteban R. Vesperoni, "Capital Inflows, Exchange Rate Flexibility and Credit Booms, IMF Working Paper, February 2012, p.19.

9 J. Cassidy, How Markets Fail: The Logic of Economic Calamities, Farrar, Straus and Giroux, 2009, p. 22.

10 Nicolas E. Magud, Carmen M. Reinhart, Kenneth S. Rogoff, "Capital Controls : Myth and Reality-A Portfolio Balance Approach", NBER Working Paper,

No.16805, (Çevrimiçi), http://www.nber.org/papers/w16805, February 2011, p.12. 
vadede ülkenin makroekonomik dengelerini bozmasında yatmaktadır. 2008 Küresel Kriz sonrası; ülkemize yönelen likidite sonucu iç talep körüklenirken zaman içerisinde üretim cephesi zayıflamış; mal ve hizmet açı̆ı ithalat yoluyla karşılanmış ve temel makroekonomik dengeler ise sarsılmıştır. Bu noktada vurgulanması gereken bir diğer husus ise; izlenen ekonomi politikaları sonucu böyle bir yapının oluşması halinde düzeltme araçlarının ve politikalarının da zor ve zaman alıcı olduğudur. Günümüzde; akademik çevre ve iş dünyası tarafından sık olarak dile getirilen yapısal önlemler uygulamaya konmadan, yıllar içerisinde oluşan tahribatı gidermek olası görünmemektedir. Yapısal reformlar ise köklü değişiklikler ve uygulamalara yol açtığından; izlenen politikaların sadece uygulayıcılar tarafından değil toplumun geniş kesimleri nezdinde de destek görmesi gerekmektedir. Toplumun ancak uzun vadede sonuç alınabileceğine inanması ve güvenmesi; yapısal reformların başarılı olabilmesi için bir önkoşuldur. Sonuç olarak; kısa vadeli sermayenin olası olumsuz etkilerini bertaraf etmek için başlangıç noktasında sermaye kontrol mekanizmalarına ihtiyaç olduğu gözlenmektedir.

Sermaye kontrolleri kapsamında özellikle verginin bir araç olarak etkinliğini belirlemek için, söz konusu verginin cari işlemler dengesine yönelik etkisini belirlemek gerekmektedir. Bununla birlikte, bir verginin arzulanan etkiyi gösterebilmesi için vergi oranının çok yüksek seviyede bulunması da önemli bir gerekliliktir. Ayrıca bu noktada zamanlamanın da önem taşıdığı da vurgulanmalıdır. Gereğinden fazla uzun sürede yürürlükte kalan verginin de makroekonomik dengeleri olumsuz yönde etkilediği göz önünde bulundurulmalıdır. Yapısal reformlar içerisinde önemli bir ağırlığa sahip olan verginin, toplum refahını artıracak şekilde düzenlenmesinin ve etkin bir vergi sisteminin oluşturulmasının az gelişmiş ve/veya gelişmekte olan ülkeler açısından önemi tartışılmazdır.11

\section{SONUÇ VE ÖNERILER}

Günümüzde sermaye hareketleri, ülke ekonomilerini şekillendiren önemli bir faktör olarak ele alınmakta ve hem akademik hem siyasi çevrelerde sık olarak sorgulanmaktadır. Gerek az gelişmiş ve/veya gelişmekte olan ülkelerde ekonomik büyüme ve kalkınma için kaynağa gereksinim olması, gerek 2008 Küresel Krizi'ni takiben dünyada artan likiditenin kar motivasyonu, sermaye hareketlerinin artmasına yol açmıştır. ABD ekonomisini canlandırma kapsamında Merkez Bankası tarafından piyasalara enjekte edilen paranın tercihi ise yüksek faiz sunması nedeniyle çoğunlukla Türkiye gibi gelişmekte olan ülkeler olmuştur. Kısa vadede sorunsuz bir şekilde işleyen söz konusu ekonomik yapı, uzun vadede gelişmekte olan ülkelerin daha fazla dış finansmana bağımlı hale gelmesine yol açmıştır. Zamanında özellikle kısa vadeli sermayeye karşı önlem almayan ülkelerin de temel makroekonomik dengelerinin bozulduğu ve hatta gerek finansal gerek reel sektör kaynaklı krizler ile karşılaştığı gözlenmiştir.

Öte yandan, dışarıdan gelen sermayenin ulusal sanayini iki yönden olumsuz etkilediği görülmüştür. İlk olarak; ucuzlayan kurlar neticesinde daha fazla hammadde ve ara malının ithal edilmesi ve ikinci olarak da nihai sanayi ürünlerinin de fiyat avantajı nedeniyle daha çok dışarıdan satın alınmasıdır. Ortaya çıkan tabloda, ekonomik büyümeyi sağlamak için cari açık verilmesi gerekli hale gelebilmektedir. Nihayetinde, ekonomik yapının sağlıklı bir yapıya kavuşabilmesi ve dış finansman bağımlılığının sebep olduğu tahribatın düzeltilebilmesi çok zaman almakta ve toplum olarak yüksek bedeller ödenmektedir.

Bu bağlamda, ulusal sanayi tahrip olmadan ve kriz sürecine girilmeden, sermaye hareketlerine yönelik kimi kontrol mekanizmalarının ve önlemlerin alınması öncelikli hedef olarak kabul edilmelidir. Söz konusu önlemler; başta para ve maliye politikaları olmak üzere Tobin vergisi diye de bilinen olarak bazı vergisel düzenlemeler olarak tanımlanmaktadır. Ekonomik büyüme için finansmana gereksinim duyan bir ülkenin öncelikli hedefi uzun vadeli, kalıcı, istihdam sağlayan ve teknoloji getiren doğrudan yabancı sermayeyi teşvik eden yatırım ortamını tesis etmek olmalıdır. Bu bağlamda bir başka önemli faktör ise, özelleştirme kapsamındaki satın almalar dışındaki, bir başka deyişle ülkede sıfırdan yeni bir tesis kurmak amacıyla gelen doğrudan yabancı sermayeye yönelik teşvik politikalarının uygulanmasıdır.

Kısa vadeli yabancı sermayeye bağımlı olmamak ve sermayenin ülkeden çıkışı durumunda olumsuz etkileri ortadan kaldırmak için bazı tedbirlerin alınmasının gerekli olduğu görülmektedir. Günümüzde, söz konusu önlemler konusunda akademik çevrelerde uzlaşma olmasa da; faiz oranları başta olmak üzere maliye ve para politikaları ile öncelikli olarak Tobin vergisi olmak üzere diğer vergi sistemleri de sorgulanmaktadır.

Yapısal reformların yapılması ve bu konuda uygulayıcılar ile toplumun geniş kesimlerinin uzlaşması ve olumlu sonuç alınması güç ve uzun vadeli bir süreçtir. Bu bağlamda, hükümet ve merkez bankası yetkilerinin ekonomide kısa vadeli getirilerden ziyade uzun vadeye odaklanmaları ve acı reçete de olsa uygulama konusunda kararlılık göstermeleri gerekmektedir. Kısa vadeli kazançların baskın olması halinde ise, ülke ekonomileri kısa vadeli dış finansmana bağlı kalmakta ve krizlere davetiye çıkarılmaktadır.

Sonuç olarak; doğrudan yabancı sermaye ve/veya iç kaynaklarla finanse edilen bir ekonomik kalkınma ve büyüme modelinin benimsenmesi halinde Türkiye, Güney Kore örneğinde olduğu gibi dünyanın büyük ekonomileri arasında yer edinme potansiyeline sahip bir ülkedir.

11 Dani Rodrik, One Economics Many Recipes : Globalization, Institutions and Economic Growth, Princeton University Press, 2007, p.17. 


\section{KAYNAKÇA}

Brookings Institute, (2011, September). Rethinking Central Banking, Committee on International Economic Policy.

Calvo, G. A. (1998). Capital Flows and Capital Market Crisis: The Simple Economics of Sudden Stops, Journal of Applied Economics, 1(1): 3554.

Calvo, G. A. Izquierdo, A. Mejia, L.F. (2004). On the Empirics of Sudden Stops: The Relevance of Balance Sheets Effects, NBER Working Paper, 10520, 22-46.

Cassidy, J. (2009). How Markets Fail: The Logic of Economic Calamities. New York, NY: Farrar, Straus and Giroux.

Chang, H.J. (1994). The Political Economy of Industrial Policy. New York, NY: St. Martin's Press.

Justiniano A. Primiceri G. (2008). The Time-Variying Volatility of Macroeconomics Fluctuations, American Economics Review, 98(3) : 604641.

Lucas, R. E., (1990, May). Why Doesn't Capital Flow from Rich to Poor Countries? The American Economic Review, Vol. 80(2) : 92-96.

Magud, N. E., Carmen M. R., Rogoff, K. S. (2011, February). Capital Controls : Myth and Reality-A Portfolio Balance Approach, NBER Working Paper, 12-27.

Magud, N.E. Reinhart, C. M. Vesperoni, E.R. (2012, February). Capital Inflows, Exchange Rate Flexibility and Credit Booms, IMF Working Paper, 19-32.

Minsky, H.P. (1993). The Financial Instability Hypothesis. Radical Political Economy, Ed. by Philip Arestis, Malcom Sawyer, NY: Edward Elgar Aldershot.

Özatay, F. (2009). Finansal Krizler ve Türkiye. İstanbul : Doğan Kitap.

Paya, M. M. (2013). Küresel Ortamda İktisat Politikaları. İstanbul: Türkmen Kitabevi.

Rodrik, D. (2007). One Economics Many Recipes : Globalization, Institutions and Economic Growth, New Jersey : Princeton University Press. 